\title{
Bentonite acrylic copolymers modified as effective oil absorbents
}

\author{
E. N. Glazacheva, M. V. Uspenskaya \& I. E. Strelnikova \\ University ITMO, Russia
}

\begin{abstract}
The oil sorption on modified bentonite granules was investigated. The sorbent is synthesized through radical polymerization of acrylic acid on the surface of Namontmorillonite. Sorption isotherms, absorption rate constant and sorption rates were determined.

Keywords: bentonite, modification, acrylic acid, polymerization, sorbent, oil spills, sorption kinetics.
\end{abstract}

\section{Introduction}

The main aim of producing effective absorbents is to find a simple synthesis method of material with high absorbing properties and low production costs.

Since bentonite is a widely abundant mineral in nature, a bentonite based absorbent can be an ecological and inexpensive material for an oil spill cleanup.

The basic component of bentonite is montmorillonite. Montmorillonite is a layered aluminosilicate mineral with a porous structure and a high cation exchange capacity. The original bentonite is able to absorb oil and oil products but without a high oil uptake capacity. In addition, natural bentonite is a hydrophilic mineral.

The porous structure, the surface area, hydrophobicity and the absorbing properties of bentonite can be changed to the desired values by its modification.

A lot of developments have been achieved in the application of bentonite as an effective absorbent [1-3].

The common method of bentonite modification is surface-active substance activation through ion-exchange reaction $[4,5]$ and acid activation $[6,7]$. These methods are very expensive and unfriendly to the environment. Hence we used the polymerization method of modification. 
Our investigation includes two parts - the synthesis of a bentonite based absorbent and the study of its swelling kinetics.

The original montmorillonite (MMT) was activated by N,N,N',N'tetramethylethylenediamine and afterwards was modified through radical polymerization of acrylic acid (AA). Ammonium persulfate (APS) was used as an initiator.

\section{Materials and methods}

\subsection{Materials}

Acrylic acid (AA; chemically pure) and ammonium persulfate (APS, analytical grade) were purchased from Vekton (Russia). Original MMT and N,N,N',N'tetramethylethylenediamine (TEMED) were obtained from Sigma-Aldrich (USA). Distilled water was used throughout the investigation.

The chemical composition of original MMT is (wt \%): $\mathrm{SiO}_{2} 63.02, \mathrm{Al}_{2} \mathrm{O}_{3}$ 21.08, $\mathrm{Fe}_{2} \mathrm{O}_{3}$ 3.25, $\mathrm{FeO} 0.35, \mathrm{MgO}$ 2.67, $\mathrm{Na}_{2} \mathrm{O} / \mathrm{K}_{2} \mathrm{O}$ 2.57, $\mathrm{CaO} 0.65, \mathrm{H}_{2} \mathrm{O}$ 5.64, trace elements 0.72 .

The fractional composition is given in table 1 .

Table 1: The fractional composition of bentonite.

\begin{tabular}{|l|c|c|}
\hline $\begin{array}{l}\text { Particle size } \\
(\mu \mathrm{m})\end{array}$ & $<74$ & $<44$ \\
\hline $\begin{array}{l}\text { Fractional } \\
\text { composition }(\%)\end{array}$ & 100.00 & 99.75 \\
\hline
\end{tabular}

\subsection{Preparations}

\subsubsection{Preparation of Na-montmorillonite}

$15 \mathrm{~g}$ of MMT powder was dispersed into $100 \mathrm{~mL}$ distilled water. The suspension solution was stirred with a mechanical stirrer for $30 \mathrm{~min}$ at room temperature. Then $1 \mathrm{~g}$ of sodium carbonate powder was added to the clay suspension and was stirred for $30 \mathrm{~min}$ at room temperature, dried for $48 \mathrm{~h}$ at room temperature and milled.

\subsection{Modification procedures}

The sorbent was prepared through radical polymerization of activated bentonite into acrylic acid in the presence of ammonium persulfate.

The synthesis procedure is as follows. The suspension of $10 \mathrm{~g}$ of $\mathrm{Na}-$ montmorillonite and $70 \mathrm{~mL}$ distilled water was prepared under stirring for 30 min at room temperature using a mechanical stirrer. A $2 \mathrm{~mL}$ of $2 \% \mathrm{~N}, \mathrm{~N}, \mathrm{~N}^{\prime}, \mathrm{N}^{\prime}-$ tetramethylethylenediamine solution was added to the suspension and stirred for $1 \mathrm{~h}$. Then $5 \mathrm{~mL}$ of acrylic acid and $2 \mathrm{~mL}$ of $2 \%$ ammonium persulfate solution 
were introduced to the mixture, stirred at room temperature until polymerization. After polymerization, the absorbent was washed several times with distilled water, filtrated and dried at room temperature for $48 \mathrm{~h}$ and then ground in an agate mortar.

\subsection{Characterization}

The oil absorption of the obtained sorbent (AA/Na-MMT) is a kinetic process. It is characterized by two parameters - sorption rate and sorption rate constant. For oil sorption kinetics investigation, the gravimetric analysis was used.

The swelling process of sorbent represents the first-order reaction eqn. (1).

$$
\frac{d Q}{d t}=K\left[Q_{\max }-Q(t)\right.
$$

where: $\mathrm{K}$ is the sorption rate constant, $\mathrm{g} / \mathrm{min} ; Q(t)$ is the swelling degree in certain time, $\mathrm{g} / \mathrm{g} ; Q_{\max }$ is the highest swelling degree, $\mathrm{g} / \mathrm{g}$.

Integrating eqn. (1), we obtain eqn. (2).

$$
K K=\frac{1}{t} \ln \frac{Q_{\max }}{Q_{\max }-Q(t)}
$$

The sorption rate $(\mathrm{g} / \mathrm{min})$ is calculated using eqn. (3).

$$
W=\frac{d Q}{d t}
$$

The absorption rate constant is connected with the swelling degree as follows:

$$
\ln \left[Q_{\max }-Q(t)\right]=\ln Q_{\max }-K \cdot t
$$

Eqn. (3) and eqn. (4) show that by using the swelling degree curve the sorption rate and sorption rate constant can be determined.

\subsubsection{Measurement of the degree of swelling}

We investigated the dependence of the degree of sorbent swelling at a constant temperature. The degree of swelling was determined by measuring the mass of swelling sorbent in time using eqn. (5).

$$
Q=\frac{m_{t}-m_{0} * w}{m_{0} * w}
$$

where: $m_{t}$ is the mass of swelling sorbent particle in certain time, $\mathrm{g} ; m_{0}$ is the initial mass of sorbent particle, $\mathrm{g} ; w$ is the moisture content of the initial sorbent particle.

Crude oil was poured into a beaker with water and a single granule of sorbent was put on an oil film. After $15 \mathrm{~min} \pm 15 \mathrm{~s}$ of immersion, the sorbent particle was removed and oil was allowed to drop out. The particle was immediately weighed using a plastic plate on the analytical balance and returned on the oil film. The plate was weighed and the mass of swelling sorbent particle was calculated using eqn (6).

$$
m_{t}=M-m_{p}
$$

where: $m_{t}$ is the mass of swelling sorbent particle in certain time, $M$ is the mass of plate with sorbent, $m_{p}$ is the mass of plate. 


\section{Results and discussion}

\subsection{Oil sorption kinetics of sorbents}

\subsubsection{The swelling curve}

The characteristic swelling curve represents the time dependence of the degree of swelling for a synthesized sorbent. By applying eqn. (5) the swelling curve was calculated. The results are shown in fig. 1 .

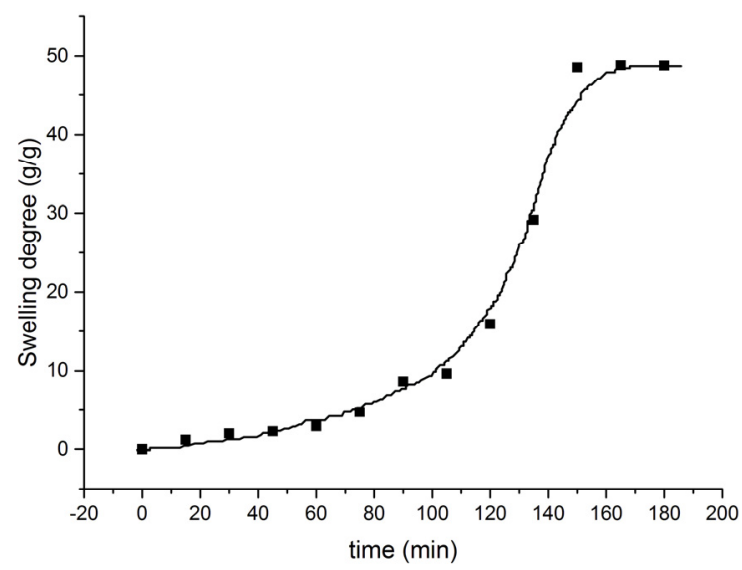

Figure 1: $\quad$ Swelling curve of sorbent at $T=297 \mathrm{~K}$.

\subsubsection{Temperature dependence of the degree of swelling}

The sorption isotherms characterize the oil sorption capacity of the sorbent. From fig. 2 it is seen that the intensity of the swelling increases as the process temperature increases.

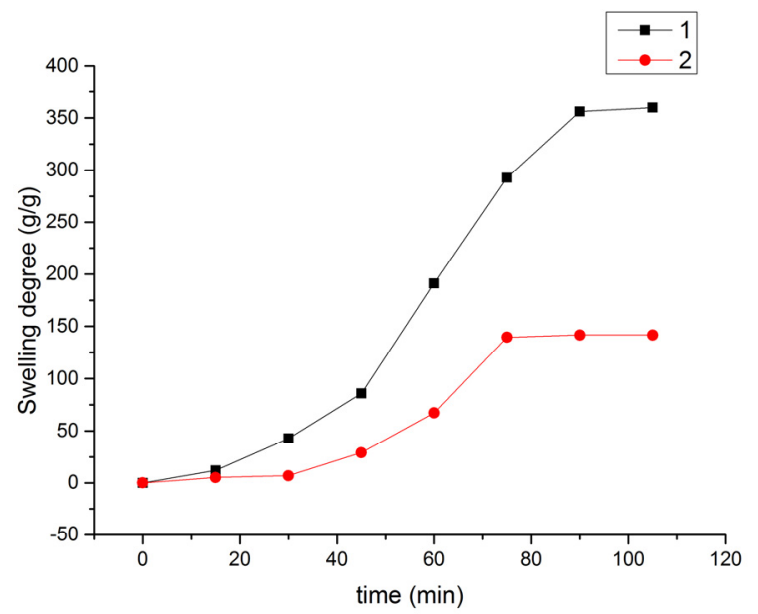

Figure 2: The dependence of swelling on temperature: $1-T=299 \mathrm{~K}$; $2-T=297 \mathrm{~K}$. 
Figs 3 and 4 shows the swelling curves for temperature of the process $278 \mathrm{~K}$ and $288 \mathrm{~K}$ correspondingly.

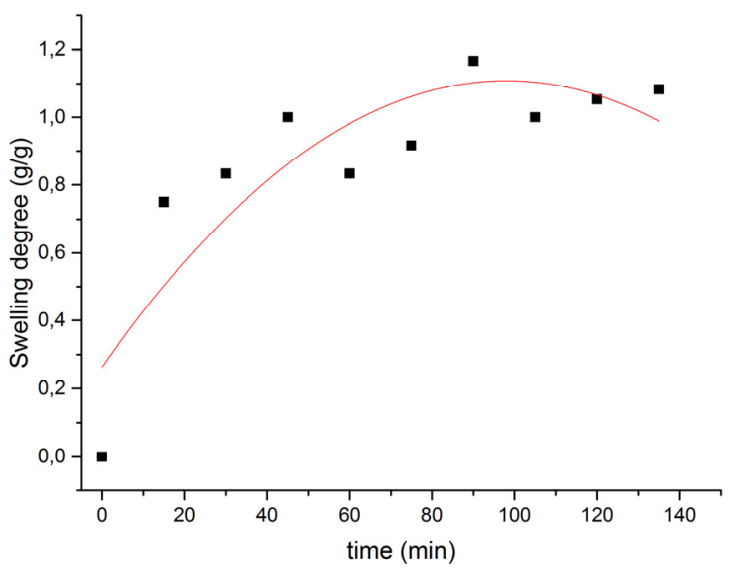

Figure 3: $\quad$ The swelling curve at $T=278 \mathrm{~K}$.

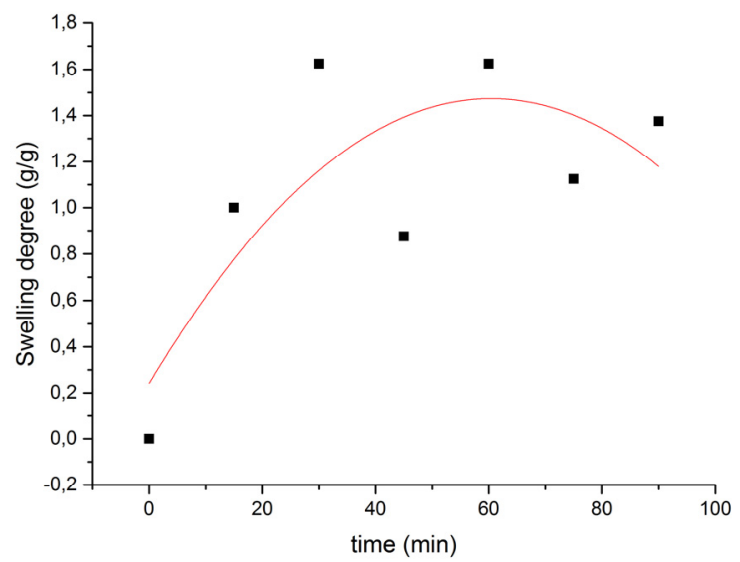

Figure 4: $\quad$ The swelling curve at $T=288 \mathrm{~K}$.

\subsubsection{Determination of sorption rates and sorption rate constants}

The sorption rates at the beginning of the process for different process temperatures were determined using eqn. (3) and the results of calculations are presented in table 2. It demonstrates that the sorption rates are higher, as the process temperature increases. 
Table 2: The sorption rates.

\begin{tabular}{|c|c|c|c|c|}
\hline $\mathrm{T}, \mathrm{K}$ & 278 & 288 & 297 & 299 \\
\hline $\mathrm{W}, \mathrm{g} / \mathrm{min}$ & 0.017 & 0.040 & 0.230 & 0.700 \\
\hline
\end{tabular}

Using eqn. (4) the kinetics curve was obtained (shown in fig. 5).

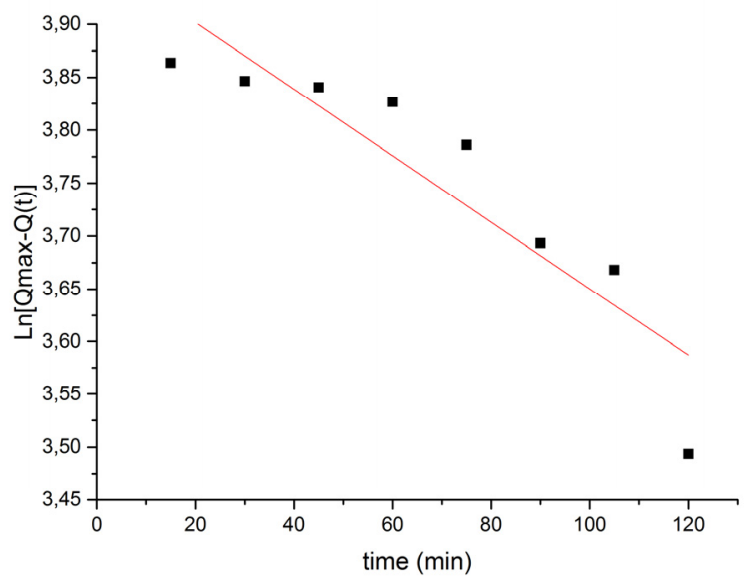

Figure 5: $\quad$ Kinetics curve at $T=297 \mathrm{~K}$.

The sorption rate constant was obtained using eqn. (7):

$$
K=\tan \alpha
$$

where: $\alpha$ is the angle of slope of kinetic line.

The calculated values of sorption rate constant are given in table 3. For different temperature the sorption rate constants are different.

Table 3: The sorption rate constants.

\begin{tabular}{|c|c|c|c|c|}
\hline $\mathrm{T}, \mathrm{K}$ & 278 & 288 & 297 & 299 \\
\hline $\mathrm{K}, \mathrm{g} / \mathrm{min}$ & 0.005 & 0.011 & 0.024 & 0.050 \\
\hline
\end{tabular}




\section{Conclusions}

A PAA/Na-MMT absorbent was synthesized through radical polymerization of AA and sodium carbonate activated MMT with TEMED and ammonium persulfate. The mass ratio of components was: 2:1 (MMT:AA). The observed sorption kinetics of modified bentonite indicates that the kinetic curve is determined by a different sorption rate of water and crude oil in a sorbent particle depending on the viscosity of a fluid. In this paper, the sorption rate constant and average sorption rates at the beginning of the process were investigated.

\section{References}

[1] Zhang, Y., Gu, Q., Dong, Z., He, P., Effect of Reaction Parameters on Swelling Properties of Poly (Acrylic Acid-Acrylamide/Montmorillonite) Nanocomposite Superabsorbents. Polymer-Plastics Technology and Engineering, 51, pp. 407-412, 2012.

[2] Prokof'ev V. Yu., Razgovorov P.B., Zakharov O.N., Gordina N.E. Study of Pore Texture of Sorbents Based on Kaolin Clay. Russian Journal of Applied Chemistry, Vol. 84, No. 11, pp. 1866-1870.

[3] Liu, Li, Zhou, Zhang, Wei, Shen. Synthesis and Properties of a Poly(acrylic acid)/Montmorillonite Superabsorbent Nanocomposite. Journal of Applied Polymer Science, Vol. 102, pp. 5725-5730, 2006.

[4] Adebajo M.O., Frost R.L., Kloprogge J.T., Carmody O., Kokot S. Porous Materials for Oil Spill Cleanup: A Review of Synthesis and Absorbing Properties. Journal of Porous Material, No. 10, pp. 159-170, 2003.

[5] Quang T. Nguyen, Donald G. Baird. Preparation of Polymer-Clay Nanocomposites and Their Properties. Advances on Polymer Technology, Vol. 25, No. 4, pp. 270-285, 2006.

[6] Kashani Motlagh M.M., Youzbashi A.A., Amiri Rigi Z. Effect of Acid Activation on Structural and Bleaching Properties of a Bentonite. Iranian Journal of Materials Science \& Engineering, Vol. 8, No. 4, pp. 50-56, 2011.

[7] Onal M., Sarikaya Y., Alemdaroglu T. The Effect of Acid Activation on Some Physicochemical Properties of a Bentonite. Turkish Journal of Chemistry, No. 26, pp. 409-416, 2002. 